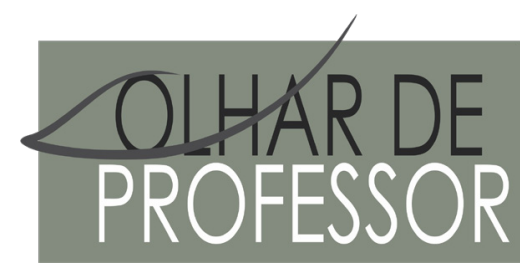

DOI: 10.5212/OLHARPROFR.v.23.2020.15326.209209229633.0721

\title{
POLÍTICAS NACIONAIS DE AVALIAÇÃO PARA A ALFABETIZAÇÃO: O QUE MUDA COM A BASE NACIONAL COMUM CURRICULAR [BNCC)?
}

\author{
NATIONAL ASSESSMENT POLICIES FOR LITERACY: WHAT DOES CHANGE WITH THE COMMON NATIONAL \\ CURRICULAR BASE?
}

POLÍTICAS NACIONALES DE EVALUACIÓN PARA ALFABETIZACIÓN: ¿QUÉ CAMBIA COM LA BASE NACIONAL COMÚN CURRICULAR?

\section{GRACIELE LIPSUCH* MICHELLE FERNANDES LIMA*}

\begin{abstract}
Resumo: Neste artigo, a problemática central delineada passa pela compreensão das mudanças nas políticas de avaliação após a aprovação da BNCC, em 2017. Inicialmente, os marcos das políticas de alfabetização após a BNCC são apresentados; também se aponta o referencial teórico em relação à temática. Na segunda seção, são analisados os documentos que norteiam o Programa Mais Alfabetização (2018), a Política Nacional de Alfabetização - PNA (2019), e o Programa Tempo de Aprender (2020). Identifica-se nos documentos analisados uma relação direta com as políticas de avaliação, com os mecanismos de controle e responsabilização docente. Também são observados um processo de antecipação da alfabetização e mecanismos de controle para o alcance de melhores índices dessa etapa, que vêm ganhando centralidade nas políticas educacionais atuais.
\end{abstract}

Palavras-chave: Políticas avaliativas. Alfabetização. Mecanismos de controle.

\begin{abstract}
In this article, the central issue designed goes through understanding the changes in the assessment policies after the approval of the BNCC in 2017. Initially, the literacy policies framework after the BNCC approval is presented, also pointing the theoretical reference regarding the theme. The second section analyzes the guiding documents of the Programa Mais Alfabetização (2018); Política Nacional de Alfabetização - PNA (2019); and the Programa Tempo de Aprender (2020). We identify that documents analyzed present a direct relationship with mechanisms of teacher control and accountability. We also observed an anticipation process of literacy and mechanisms of control to achieve better indexes in this stage, which have gaining centrality in the current educational policies.
\end{abstract}

Keywords: Assessment policies. Literacy. Mechanisms of control.

Resumen: En este artículo, la problemática central pasa por la compresión de los cambios en las políticas de evaluación después de aprobación de la BNCC en 2017. Inicialmente, los marcos de las políticas de alfabetización después de la BNCC son presentados, también se apunta el referencial teórico relacionado con el tema. En la segunda sección, los documentos que guían el Programa Mais Alfabetização (2018), la Política Nacional de

\footnotetext{
* Graduada em Pedagogia pela Universidade Estadual do Centro-Oeste/ UNICENTRO, mestranda em educação (PPGE/ UNICENTRO). Bolsista CAPES. Pesquisadora no Grupo de Pesquisa Estado, Políticas e Gestão da Educação (UNICENTRO/ IRATI-PR). E-mail: gracielelipsuch@outlook.com

${ }^{* *}$ Mestre em fundamentos da educação pela Universidade Estadual de Maringá, Doutora em educação pela UFPR, Pós Doutora pela UEPG. Professora do Departamento de pedagogia, e do Programa de Pós Graduação em Educação da Universidade Estadual do Centro-Oeste (PPGE/UNICENTRO). Líder do Grupo de Pesquisa Estado, Políticas e Gestão da Educação (UNICENTRO/IRATI-PR).E-mail: mfernandeslima@yahoo.com.br
} 
Alfabetização - PNA (2019), y el Programa Tempo de Aprender (2020) son analizados. Se identifica que los documentos analizados presentan relación directa con las políticas de evaluación, con los mecanismos de control y responsabilización docente. También son observados un proceso de anticipación de la alfabetización y mecanismos de control para alcanzar mejores índices de esa etapa, que ha ganado centralidad en las políticas educacionales actuales.

Palabras-clave: Políticas evaluativas. Alfabetización. Mecanismos de control.

\section{INTRODUÇ̃̃O}

Este artigo é parte integrante da pesquisa intitulada Políticas de avaliação para a alfabetização no Brasil e a Base Nacional Comum Curricular (BNCC): novos (velhos) mecanismos de controle e responsabilização, desenvolvida no curso de Mestrado em Educação da Universidade Estadual do CentroOeste (UNICENTRO/PR). Também está vinculada ao Grupo de Pesquisa Estado, Políticas e Gestão da Educação (UNICENTRO/ Irati - PR) ${ }^{1}$.

No presente artigo, buscamos discutir os novos delineamentos para as políticas avaliativas voltadas à alfabetização após a aprovação da Base Nacional Comum Curricular da Educação Infantil e do Ensino Fundamental (BNCC), em 2017. Para isto, a questão central que nos propomos a refletir foi: O que muda na alfabetização, essencialmente na questão da avaliação nacional dessa etapa de ensino a partir da BNCC? Assim, objetivamos identificar os novos marcos das políticas voltadas à alfabetização no Brasil, enfatizando a questão avaliativa por meio de pesquisa bibliográfica e documental.

Compreendemos que as políticas avaliativas se fazem presentes em um determinado modelo societário, e que esse modelo tem determinada concepção de educação. Isto faz parte de um processo muito mais amplo de um conjunto de políticas delineadas para a educação no Brasil. Concordamos com Afonso (2009, p. 19), quando afirma que a avaliação é, também, uma atividade política: “as funções da avaliação têm que ser, por isso, compreendidas no contexto das mudanças económicas e políticas mais amplas”.

Compreendemos o Estado como um ordenamento jurídico e político que, na abordagem de Antonio Gramsci (1968), é formado pela sociedade civil (aparelhos privados de hegemonia) e sociedade política (aparelhos de coerção). Em outras palavras, esses dois elementos resultam no Estado revestido de coerção, no qual há predominância dos interesses hegemônicos.

O Estado, na sociedade capitalista e pautado nos ideais liberais, assume como pressuposto essencial a defesa da propriedade privada, a divisão de classes sociais e a exploração do trabalho. Tais aspectos são essenciais e sempre estão presentes nesse tipo de conjuntura. No entanto, o liberalismo assumiu diferentes formas ao longo do tempo, tal como o neoliberalismo, mas sempre mantendo seus aspectos essenciais (LIMA, 2005).

A atuação dos diferentes governos pode se apresentar com características mais democráticas, menos democráticas, ou mais autoritárias, mas sua base, sua essência de Estado burguês permanece, visto que a democracia não ocorre plenamente na sociedade capitalista. No Brasil, a atual sociedade capitalista está pautada pelos ideais neoliberais que começaram a se desdobrar nos anos de 1980 e ganharam intensidade nos anos de 1990, perpassaram-se e seguidamente ampliaram-se com a postura e políticas dos governos federais que assumiram a presidência.

Esses princípios neoliberais são abertamente defendidos por organismos internacionais, como Banco Mundial (BM) e Organização para a Cooperação e o Desenvolvimento Econômico (OCDE), que atuam fortemente na elaboração de grandes eventos e produção documental para a educação. Consequentemente, influenciam as políticas educacionais, principalmente dos países periféricos, visto que o compromisso

\footnotetext{
${ }^{1}$ O Grupo foi criado em 2013, conta com a participação de alunos e professores da graduação e pós-graduação, e tem como objetivo a produção de estudos e pesquisas sobre as transformações sociais, econômicas e políticas e seus reflexos no campo educacional, bem como o perfil e papel do Estado frente às políticas educacionais. Para conhecer mais, ver: https://www2. unicentro.br/gepoge/.
} 
com a efetivação de suas prescrições são um dos elementos necessários para a concessão de empréstimos (FRIGOTTO; CIAVATTA, 2003; SILVA, 2002).

Com essas orientações internacionais pautadas na ideologia neoliberal, observamos, no Brasil nas décadas de 1980 - 1990, a implementação de mecanismos de avaliação educacional em larga escala, que ganharam maior expressividade com o Sistema de Avaliação da Educação Básica (SAEB). A implementação de avaliações em larga escala está em consonância com a educação pensada para o projeto capitalista, que forme pessoas habilitadas e competentes para as demandas do mercado. Nessa perspectiva, a educação é tomada e baseada no modelo gerencialista, o qual busca, entre outros aspetos, a eficácia e a eficiência das unidades escolares.

Um dos fatores que deram maior visibilidade ao Sistema de Avaliação da Educação Básica foi a aprovação da Base Nacional Comum Curricular (BNCC), a qual, durante a fase de elaboração, teve forte atuação de instituições privadas. Essa atuação empresarial na educação faz-se muito presente atualmente, com o discurso da necessidade de contribuir para a melhoria educacional (D’AVILA, 2018). Desta forma, via parcerias público-privadas, empresas passaram a enxergar a educação como um negócio, orientada por mecanismos de quase-mercado.

Ao mesmo tempo que a educação se torna um serviço não exclusivo do Estado, a avaliação continua sendo um mecanismo de controle dos governos, que assumem uma postura de Estado-avaliador. Observamos, assim, que o Estado muda de configuração, e o Sistema de Avalição da Educação Básica, que é um critério inclusive para efetivação de empréstimos internacionais, permanece.

Enquanto isso, mecanismos de avaliação, controle e responsabilização abalam o trabalho docente, que passa a ser muito mais controlado para o alcance de bons resultados, em detrimento de uma educação de qualidade.

Considerando a proposta desta pesquisa, estruturamos o artigo em duas seções, além desta introdução e das considerações finais. Na primeira seção foram levantados os marcos das políticas educacionais de alfabetização no Brasil, com base nos documentos voltados para essa etapa, priorizando as políticas mais recentes após a aprovação da BNCC. Assim, identificamos como a alfabetização é entendida nos diferentes documentos, qual a perspectiva de diversos autores da área, bem como abordamos os novos desdobramentos das políticas para a alfabetização, que vêm ganhando centralidade na agenda política educacional brasileira.

Na segunda seção foram elencadas as seguintes políticas educacionais e seus consequentes documentos para análise: Programa Mais Alfabetização: Portaria n ${ }^{\circ}$ 142, de 22 de fevereiro de 2018 (BRASIL, 2018b); Política Nacional de Alfabetização: Decreto nº 9.765, de 11 de abril de 2019 (BRASIL, 2019a); Cartilha da Política Nacional de Alfabetização (BRASIL, 2019b); e o Programa Tempo de Aprender: Portaria $n^{\circ} 280$, de 19 de fevereiro de 2020 (BRASIL, 2020b). Estes documentos foram selecionados por representarem a mais atual orientação legal para a etapa da alfabetização. A partir desses documentos, buscamos identificar como a questão da avaliação em larga escala está sendo contemplada para a etapa de alfabetização.

\section{NOVOS MARCOS DAS POLÍTICAS DE ALFABETIZAÇÃO NO BRASIL: EM DESTAQUE, OS DOCUMENTOS}

Nesta seção, buscamos discutir as políticas voltadas para a alfabetização e os novos delineamentos para essa etapa de ensino após a aprovação da Base Nacional Comum Curricular (BNCC). Por meio da identificação das políticas mais recentes, observamos que a alfabetização tornou-se algo imprescindível na agenda política da atualidade, e que os esforços para a melhoria da qualidade da alfabetização são aqueles direcionados para o alcance de bons índices e resultados, buscando reverter os baixos desempenhos e os grandes índices de analfabetismo no país.

Em relação à etapa de escolarização que compreende a alfabetização, observamos vários marcos importantes nos últimos anos, visto que essa etapa vem gradativamente ganhando destaque e sofrendo algumas alterações no cenário educacional. Observamos que a formação continuada de professores alfabetizadores foi efetivada por vários programas, como o Programa de Formação de Professores 
Alfabetizadores (PROFA)², o Pró-letramento ${ }^{3}$, e o Pacto Nacional pela Alfabetização na Idade Certa (PNAIC). Além desses programas, também surgiram políticas específicas voltadas para a melhoria da qualidade da alfabetização, algumas das quais serão elencadas posteriormente.

Devido aos baixos resultados do SAEB em relação ao desempenho dos alunos, o governo tomou a iniciativa de reverter a situação por meio da implantação do Plano de Metas Compromisso Todos pela Educação, que apresenta a necessidade de alfabetizar as crianças até os 08 anos de idade; a criação do PNAIC; bem como a aferição do desempenho dos estudantes por meio da Provinha Brasil, cuja primeira aplicação ocorreu em 2008.

Em 2007 foi criada a Provinha Brasil, sendo uma avaliação diagnóstica, composta por questões de Língua Portuguesa e Matemática, com a proposta de investigar as habilidades desenvolvidas pelos estudantes do $2^{\circ}$ ano do Ensino Fundamental - Anos Iniciais. Como é uma avaliação sem fins pedagógicos, gera informações a professores e gestores ${ }^{4}$.

Outro marco importante é o Programa Federal Pacto Nacional Pela Alfabetização na Idade Certa (PNAIC), o qual foi instituído em 2012, com a proposta de melhorar o processo de alfabetização. Seu eixo central é a formação continuada de professores alfabetizadores, também envolvendo ações, materiais e referências pedagógicas e curriculares disponibilizadas pelo Ministério da Educação. A Portaria que então tinha instituído o programa foi revogada por outra, a Portaria n 826, de 7 de julho de 2017 (BRASIL, 2017a), a qual dispõe sobre o Pacto Nacional pela Alfabetização na Idade Certa - PNAIC, suas ações, diretrizes gerais e a ação de formação no âmbito do Programa Novo Mais Educação - PNME. A partir desta Portaria, o PNAIC passa a abranger:

I - a alfabetização em língua portuguesa e em matemática;

II - a realização de avaliações com foco na alfabetização, pelo Instituto Nacional de Estudos e Pesquisas Educacionais Anísio Teixeira - INEP; e

III - o apoio gerencial, técnico e financeiro aos entes que tenham aderido às ações do PNAIC, para sua efetiva implementação (BRASIL, 2017a, p. 20).

Além disso, como dispõe o Artigo 03 da Portaria, fica instituída a ação de formação no âmbito do Programa Novo Mais Educação - PNME para melhorar a aprendizagem dos alunos em Língua Portuguesa e Matemática.
Art. $5^{\circ}$ As ações de formação do PNAIC e do PNME têm por objetivos:
I - garantir que todos os estudantes dos sistemas públicos de ensino estejam alfabetizados, em Língua Portuguesa e em Matemática, até o final do $3^{\circ}$ ano do ensino fundamental;
II - reduzir a distorção idade-série na Educação Básica;
III - melhorar o Índice de Desenvolvimento da Educação Básica - IDEB; e
IV - contribuir para o aperfeiçoamento do desempenho dos professores (BRASIL, 2017a, p. 20).

A partir de tais pressupostos, podemos observar a direta ligação entre esses programas e as avaliações em larga escala, pois são elas que geram os índices educacionais e acabam responsabilizando os professores pelo desempenho da escola e dos alunos. A partir disto, cria-se a ideia de que o bom professor é aquele cujos alunos tiveram bons desempenhos nos índices. Para evidenciar essa perspectiva, basta observar que, a partir do PNAIC, surgiu uma avaliação em larga escala para a alfabetização, a Avaliação Nacional da Alfabetização (ANA).

Como previsto no PNAIC, em 2013 foi criada a Avaliação Nacional da Alfabetização, destinada aos alunos do $3^{\circ}$ ano do Ensino Fundamental, até então considerado o ano final do ciclo de alfabetização. A aplicação da ANA foi realizada nos anos de 2013, 2014 e 2016, e com os novos delineamentos

\footnotetext{
${ }^{2}$ Foi um programa de formação continuada de professores alfabetizadores, lançado em 2000. O principal objetivo do PROFA foi desenvolver competências necessárias para os docentes ensinarem a ler e escrever.

${ }^{3}$ Lançado em 2005 é um programa de formação continuada de professores, que visa melhorar a aprendizagem nos anos/séries iniciais do Ensino Fundamental em leitura/escrita e matemática, realizado pelo Ministério da Educação em parceria com universidades que integraram a Rede Nacional de Formação Continuada, tendo adesão dos estados e municípios.

${ }^{4}$ Mais informações em: http://portal.inep.gov.br/provinha-brasil.
} 
do SAEB, depois da aprovação da BNCC, ela deixou de existir. No entanto, as alterações do SAEB de 2019, previam a realização de uma avaliação para a alfabetização para o $2^{\circ}$ ano do Ensino Fundamental, visto que, com a aprovação da BNCC, a alfabetização passa a ser até o $2^{\circ}$ ano, e não mais até o $3^{\circ}$ ano do Ensino Fundamental. O documento dispõe que,

Embora, desde que nasce e na Educação Infantil, a criança esteja cercada e participe de diferentes práticas letradas, é nos anos iniciais ( $1^{\circ} \mathrm{e} 2^{\circ}$ anos) do Ensino Fundamental que se espera que ela se alfabetize. Isso significa que a alfabetização deve ser o foco da ação pedagógica. Nesse processo, é preciso que os estudantes conheçam o alfabeto e a mecânica da escrita/ leitura - processos que visam a que alguém (se) torne alfabetizado, ou seja, consiga "codificar e decodificar” os sons da língua (fonemas) em material gráfico (grafemas ou letras), o que envolve o desenvolvimento de uma consciência fonológica (dos fonemas do português do Brasil e de sua organização em segmentos sonoros maiores como sílabas e palavras) e o conhecimento do alfabeto do português do Brasil em seus vários formatos (letras imprensa e cursiva, maiúsculas e minúsculas), além do estabelecimento de relações grafofônicas entre esses dois sistemas de materialização da língua (BRASIL, 2018a, p. 89-90).

Nesse sentido, a alfabetização está articulada a fim de que os estudantes possam se apropriar do sistema de escrita alfabética, bem como de habilidades de leitura e escrita (BRASIL, 2018a).

Essa antecipação da alfabetização, com a BNCC, vem sendo discutida e criticada por diversos autores, que afirmam que a concepção de currículo na BNCC, principalmente na questão da alfabetização, é reduzida a uma tendência tecnicista.

A concepção de currículo na BNCC traz uma perspectiva tecnicista e redutora dos conhecimentos sobre a alfabetização, aparentemente articulados, que escamoteiam os interesses do capital neoliberal que toma qualidade como competência. Nessa perspectiva está distante de uma escola como lugar de constituição humana de seus alunos por meio de uma educação transformadora em que o processo de apropriação da cultura escrita pelos alfabetizandos tem um papel fundamental (BORTOLANZA; GOULART; CABRAL, 2018, p. 978-979).

A alfabetização é uma das metas mais importantes a serem atingidas pela educação, visto que ela abre as portas para os direitos e deveres dos cidadãos. O conceito de alfabetização é construído por diferentes abordagens, técnicas, métodos e tendências teóricas. Nos Parâmetros Curriculares Nacionais (PCNs), verifica-se a perspectiva construtivista, enquanto a BNCC renega o construtivismo e apresenta um viés voltado para o método fônico (FERNANDES; COLVERO, 2019). Nessa mesma perspectiva, Amarante e Moreira (2019) afirmam que, além de prever a alfabetização até o $2^{\circ}$ ano do Ensino Fundamental, a BNCC

[...] propõe um trabalho sistemático apenas com a mecânica da alfabetização, a qual delimita o processo de apropriação da escrita apenas à decifração do código. Dessa forma, analisa-se que a aquisição do sistema de escrita é reduzida apenas aos conhecimentos dos sons das letras, das sílabas e das palavras, priorizando as propriedades fonológicas da língua [...] (AMARANTE; MOREIRA, 2019, p. 14).

Para as autoras, no que diz respeito à alfabetização, a BNCC é reduzida à leitura e a escrita, e há predominância da técnica da escrita. Como discorrem Fernandes e Colvero (2019, p. 288), a BNCC, além de ser contrária ao PNE no que diz respeito à alfabetização,

[...] desconsidera o que especialistas nas áreas da linguística, da neuropediatria, da pedagogia e da psicopedagogia afirmam em relação à idade ideal ou adequada para inserir as crianças em um contexto de alfabetização, isto é, a partir dos seis anos de idade. Isso sugere que pode ser um tempo muito curto entre o inserir a criança em um contexto de alfabetização (a partir dos seis anos) e ela se tornar alfabetizada (aos sete anos), uma vez que cada criança desenvolve sua aprendizagem de forma individualizada.

Como expõem Bortolanza, Goulart e Cabral (2018, p. 969), "escrever requer muito mais que habilidade cognitiva e motora de registrar grafemas relacionando-os a fonemas como expõe a BNCC”. As autoras 
defendem a perspectiva histórico-cultural, na qual a aprendizagem da leitura e da escrita é um processo que atribui significado e sentido ao ato de ler e escrever, na proposta de uma educação transformadora.

A BNCC ainda prevê uma articulação da etapa da Educação Infantil e do Ensino Fundamental.

A BNCC do Ensino Fundamental - Anos Iniciais, ao valorizar as situações lúdicas de aprendizagem, aponta para a necessária articulação com as experiências vivenciadas na Educação Infantil. Tal articulação precisa prever tanto a progressiva sistematização dessas experiências quanto o desenvolvimento, pelos alunos, de novas formas de relação com o mundo, novas possibilidades de ler e formular hipóteses sobre os fenômenos, de testá-las, de refutá-las, de elaborar conclusões, em uma atitude ativa na construção de conhecimentos (BRASIL, 2018a, p. 57-58, grifos originais).

Entretanto, apesar de prever um conjunto orgânico e progressivo de aprendizagens, as estruturas apresentadas no documento são diferentes nessas duas etapas. Isso porque a Educação Infantil está organizada por campos de experiências, e o Ensino Fundamental por áreas do conhecimento. "Essa diferença na apresentação das estruturas normativas para as etapas da educação básica pode gerar uma dificuldade no reconhecimento da progressão das aprendizagens entre elas" (BORTOLANZA; GOULART; CABRAL, 2018, p. 973). Além disso, como destacam Amarante e Moreira (2019, p. 11-12),

[...] corre-se o risco dos novos currículos tornarem as práticas pedagógicas na educação infantil mais escolarizantes e menos lúdicas, isto é, preparar o aluno para o ensino fundamental, uma vez que a BNCC (2017) conduz o trabalho com a alfabetização desde a educação infantil [...].

Com a BNCC aprovada para a Educação Infantil e o Ensino Fundamental, identificamos novos delineamentos para a alfabetização. Com a aprovação da BNCC surgiu, posteriormente, o Programa Mais Alfabetização (PMALFA), criado pela Portaria n 142, de 22 de fevereiro de 2018 (BRASIL, 2018b). Tal Portaria expõe que o Programa tem como objetivo fortalecer e apoiar as unidades escolares no processo de alfabetização, com os alunos regularmente matriculados no $1^{\circ}$ e no $2^{\circ}$ ano do Ensino Fundamental.

Art. $2^{\circ} \mathrm{O}$ Programa tem por finalidade contribuir para:

I - a alfabetização (leitura, escrita e matemática) dos estudantes regularmente matriculados no $1^{\circ}$ ano e no $2^{\circ}$ ano do ensino fundamental, por meio de acompanhamento pedagógico específico; e II - a prevenção ao abandono, à reprovação, à distorção idade/ano, mediante a intensificação de ações pedagógicas voltadas ao apoio e fortalecimento do processo de alfabetização (BRASIL, 2018b, p. 54).

O programa conta com a participação de um assistente de alfabetização como apoio adicional, com o período de cinco horas semanais nas unidades escolares não vulneráveis, ou de dez horas semanais nas unidades escolares vulneráveis, sendo a participação do assistente voluntária, realizada por meio da assinatura do termo de compromisso.

O Programa Mais Alfabetização, juntamente com o Programa Nacional da Alfabetização na Idade Certa (PNAIC), integra a Política Nacional de Alfabetização brasileira. Um aspecto importante é que algumas das justificativas para a implantação do PMALFA foram a aprovação da BNCC e os baixos resultados na Avaliação Nacional da Alfabetização (ANA) em $2016^{5}$.

Considerando as incumbências dos envolvidos no programa, destaca-se que o MEC é responsável por implementar mecanismos de monitoramento, com avaliações diagnósticas e formativas. A implantação do Programa Mais Alfabetização é um dos aspectos que podem ser observados nas mudanças educacionais realizadas a partir da BNCC.

\footnotetext{
${ }^{5}$ Matemática: a porcentagem de estudantes nos níveis 3 e 4 ficou em 45,5\% em 2016. Assim, mais da metade dos estudantes brasileiros, 54,4\%, ainda está abaixo do desempenho desejável, estando nos níveis 1 e 2 . Leitura: 45,2\% dos estudantes avaliados obtiveram níveis satisfatórios em Leitura, com desempenho nos níveis 3 e 4 e 54,7\% dos estudantes estão nos níveis 1 e 2. Escrita: 66,15\% dos estudantes nos níveis 4 e 5. No entanto, ainda 33,95\% dos estudantes estão nos níveis insuficientes: 1 , 2 e 3. Mais informações em: http://portal.inep.gov.br/artigo/-/asset_publisher/B4AQV9zFY7Bv/content/mec-anuncia-politica-nacional-de-alfabetizacao-para-reverter-quadro-de-estagnacao-na-aprendizagem/21206 (BRASIL, 2017b).
} 
No atual governo, do presidente Jair Messias Bolsonaro, foi aprovado o Decreto $\mathrm{n}^{\circ}$ 9.765, de 11 de abril de 2019 (BRASIL, 2019a), que instituiu a Política Nacional de Alfabetização (PNA), com a finalidade de melhorar a qualidade da alfabetização no Brasil. Também visa combater o analfabetismo absoluto e o analfabetismo funcional.

A PNA está pautada, como dispõe o Art. 03 do Decreto, em seis componentes essenciais para a alfabetização: consciência fonêmica, instrução fônica sistemática, fluência em leitura oral, desenvolvimento de vocabulário, compreensão de textos, e produção de escrita (BRASIL, 2019a). Como apresentado no Decreto, no Art. 4, que trata dos objetivos da PNA, eles são:

I - elevar a qualidade do ensino e da aprendizagem no âmbito da alfabetização, da literacia e da numeracia, sobretudo nos primeiros anos do ensino fundamental, por meio de abordagens cientificamente fundamentadas;

II - contribuir para a consecução das Metas 5 e 9 do Plano Nacional de Educação [...]

III - assegurar o direito à alfabetização a fim de promover a cidadania e contribuir para o desenvolvimento social e econômico do País;

IV - impactar positivamente a aprendizagem no decorrer de toda a trajetória educacional, em suas diferentes etapas e níveis; e

V - promover o estudo, a divulgação e a aplicação do conhecimento científico sobre literacia, alfabetização e numeracia (BRASIL, 2019a, p. 16).

A adesão a PNA é voluntária aos entes federados, na colaboração da política que será implementada por meio de programas, ações e instrumentos. O documento afirma, ainda, que a prioridade será dada à alfabetização no $1^{\circ}$ ano do Ensino Fundamental.

Ressalta-se que "a PNA, com base na ciência cognitiva da leitura, define alfabetização como o ensino das habilidades de leitura e de escrita em um sistema alfabético" (BRASIL, 2019b, p. 18, grifos originais). Sobre a atual PNA, Amarante e Moreira (2019) afirmam que essa política prioriza o método fônico, ao referirem-se à consciência fonêmica e instrução fônica.

Acreditamos que atribuir o insucesso da alfabetização unicamente ao método utilizado nas salas de aula culpabiliza somente os professores, sem considerar, na atual conjuntura, a necessidade da elaboração de políticas públicas em nível de Estado que favoreçam a equidade dos estudantes ao acesso à cultura escrita (AMARANTE; MOREIRA, 2019, p. 17).

A partir desses pressupostos, observamos a ênfase que é dada à alfabetização e ao trabalho do professor alfabetizador, que vem sendo cada vez mais cobrado. Ressalta-se, ainda, que a partir da Política Nacional de Alfabetização lançada em 2019, surgiram novos desdobramentos na política educacional.

Em entrevista ao Portal MEC em 2019 (BRASIL, 2019c), intitulada Programa de alfabetização será prioridade em 2020, o Secretário Carlos Nadalim ${ }^{6}$, responsável pela Secretaria de Alfabetização (SEALF), afirmou que as perspectivas para 2020 são continuar com as ações já desenvolvidas e a criação de um programa específico de alfabetização. Segundo o secretário, a primeira ação da PNA foi a adesão ao Progress in International Reading Literacy Study (PIRLS), que é uma avaliação internacional de leitura, aplicada aos alunos do $4^{\circ}$ ano do Ensino Fundamental. Outro desdobramento da PNA foi a Conferência Nacional de Alfabetização Baseada em Evidência, a Conabe, realizada em 2019. Sobre as ações desta Conferência, o Secretário dispõe:

Ainda no primeiro semestre de 2020, a Sealf apresentará o fruto desses debates, o Relatório Nacional da Alfabetização Baseada em Evidências (Renabe). O documento apresentará sugestões para as políticas nacionais relacionadas à alfabetização, com as evidências científicas mais robustas e atualizadas que nortearão as ações da secretaria de alfabetização (BRASIL, 2019c).

\footnotetext{
${ }^{6}$ Carlos Nadalim é formado em Direito pela Universidade Estadual de Londrina (UEL), possui especialização em História e Teorias da Arte, especialização em Filosofia Moderna e Contemporânea e mestrado em Educação pela mesma instituição. Assumiu a Secretaria de Alfabetização em 2019 no governo de Jair Messias Bolsonaro.
} 
Outra novidade que está intimamente relacionada à Política Nacional de Alfabetização foi o lançamento do programa Conta pra Mim, o qual valoriza e incentiva a participação da família no processo alfabetizador.

Em entrevista disponível na página eletrônica do MEC (BRASIL, 2019c), o Secretário de Alfabetização, Carlos Nadalim, explica as perspectivas do programa Conta pra Mim, conforme excerto abaixo:

No primeiro semestre de 2020, abriremos o processo de adesão para que os entes federados participem, voluntariamente, do programa. Eles receberão assistência técnica e financeira. Vamos capacitar tutores que conduzirão sessões de literacia familiar nos espaços Conta pra Mim. Nossa expectativa é alcançar 1 milhão de famílias e criar 5 mil cantinhos Conta pra Mim. O orçamento disponível para o programa é de R 45 milhões (BRASIL, 2019c).

$\mathrm{O}_{\mathrm{MEC}}^{7}$ (BRASIL, 2020a), por meio do programa Conta pra Mim, disponibiliza materiais para orientação de práticas de Literacia Familiar, por meio de vídeos e um Guia de Literacia Familiar que pode ser baixado, além de disponibilizar orientações do Programa de Promoção de Literacia Familiar. Conforme exposto pelo MEC na apresentação do programa, a participação dos pais é fundamental para a aprendizagem da leitura e da escrita, e afirma: "Reconhecendo a importância da família, o Ministério da Educação criou o programa Conta pra Mim, que ajudará você a ser o herói de seu filho” (BRASIL, 2020a).

A participação da família no contexto alfabetizador é defendida pela Política Nacional de Alfabetização (PNA) que, em seu caderno, dispõe:

O êxito das crianças na aprendizagem da leitura e da escrita está fortemente vinculado ao ambiente familiar e às práticas e experiências relacionadas à linguagem, à leitura e à escrita que elas vivenciam com seus pais, familiares ou cuidadores, mesmo antes do ingresso no ensino formal (BRASIL, 2019b, p. 23).

Essa perspectiva também é amplamente defendida por Carlos Nadalim, responsável pela Secretaria de Alfabetização (SEALF) criada em 2019, a qual é responsável pelo planejamento, orientação e coordenação de ações voltadas à alfabetização, conforme já exposto. Em seu Blog intitulado Como Educar seus Filhos8, Carlos Nadalim publica vídeos defendendo a alfabetização pelo método fônico, afirmando que, no Brasil, o letramento é o vilão da alfabetização.

Como podemos identificar, existem vários documentos e programas que norteiam a alfabetização no Brasil, mas, observando os documentos, notamos discordância e contradição entre eles, no que diz respeito aos anos destinados à alfabetização.

O PMALFA estabelece orientações contraditórias e desconexas em relação ao PNAIC. Apesar das contradições, os dois programas, como disposto na Portaria n 142, de 22 de fevereiro de 2018 (BRASIL, 2018b), fazem parte da Política Nacional de Alfabetização. Além disso, a PNA, que tem como um dos objetivos contribuir para o alcance das Metas do PNE, também apresenta contradições, pois, como dispõe o PNE na Meta 5, é preciso "alfabetizar todas as crianças, no máximo, até o final do $3^{\circ}$ (terceiro) ano do ensino fundamental (BRASIL, 2014, p. 10). No entanto, o Decreto que instituiu a PNA dispõe, em seu Art. $5^{\circ}$, as diretrizes para implementação da PNA, e a primeira diretriz apresentada é "I - priorização da alfabetização no primeiro ano do ensino fundamental” (BRASIL, 2019a), enquanto na BNCC, a alfabetização deve ocorrer nos dois primeiros anos do Ensino Fundamental. Com isto, observamos a discordância entre as diretrizes que regem a alfabetização. A PNA justifica essa antecipação afirmando que a

[...] priorização da alfabetização no $1^{\circ}$ ano do ensino fundamental é uma diretriz de implementação da PNA que beneficia sobretudo as crianças mais pobres, visto que estas, diferentemente das crianças de nível socioeconômico mais elevado, muitas vezes não encontram em casa o estímulo a práticas de literacia e por isso costumam ter mais dificuldades em aprender a ler e a escrever (BRASIL, 2019b, p. 41).

\footnotetext{
${ }^{7}$ Mais informações em: http://alfabetizacao.mec.gov.br/\#para-pais.

${ }^{8}$ Mais informações em: http://comoeducarseusfilhos.com.br/blog/
} 
Diante dessa contradição entre os documentos, Fernandes e Colvero (2019) questionam qual das orientações e normas devem ser seguidas pelos gestores e professores. Em termos de legislação, qual é a norma superior, e o que deve ser levado em consideração quando, para uma mesma etapa de ensino, são apresentadas divergências nas normatizações. Considerando a Pirâmide de Kelsen ${ }^{9}$, os autores evidenciam que a Constituição Federal está acima de todas leis; em seguida está o PNE, que é uma lei; e posteriormente a BNCC, que é uma Resolução; em seguida, as Portarias dos programas do PNAIC e PMALFA.

Assim, pode-se afirmar que a BNCC, no que se refere à alfabetização, não é válida dentro do ordenamento jurídico o qual é abrangido pelo PNE. Nesse contexto, pode-se inferir que há uma tentativa de imposição de uma política pública de governo (a BNCC, quanto à alfabetização) sobre uma política pública de Estado (o PNE, quanto à meta 5) (FERNANDES; COLVERO, 2019, p. 301).

Considerando todo esse aparato legal, podemos observar que as políticas curriculares orientam os projetos formativos do homem, e estão diretamente articuladas com um modelo societário. Neste viés, a BNCC pode ser considerada uma lista que compreende determinadas habilidades e competências vistas como uma formação ideal para o modelo societário capitalista.

Sobre a BNCC, Bortolanza, Goulart e Cabral (2018, p. 962) evidenciam que, "nesse cenário neoliberal, em que tudo se transforma em lucro e mercadoria, a concepção de currículo na BNCC apresenta uma visão estreita e tecnicista trazendo os conhecimentos fragmentados sob a aparência de uma suposta neutralidade".

A alfabetização mantém-se na agenda política devido à necessidade histórica de superar os grandes índices de analfabetismo no país. No entanto, muitas políticas não têm continuidade devido à alteração de governos, e por isso a necessidade de uma política de Estado efetiva para a alfabetização. Amarante e Moreira (2019), assim como Fernandes e Colvero (2019), defendem uma Política Nacional de Estado, no que tange à alfabetização que em curto, médio e longo prazo, todos os entes federados comprometam-se em uma política efetiva para a melhoria da alfabetização. Isto porque

Decretar que a alfabetização se dê até o $1^{\circ}$, o $2^{\circ}$ ou o $3^{\circ}$ ano não resolve o problema, apenas pressiona os envolvidos nesse processo, particularmente crianças, para atingir as metas estipuladas e responsabiliza professores quando essas metas não são atingidas (FERNANDES; COLVERO, 2019, p. 294).

A BNCC, ao padronizar uma base curricular mínima tanto para escolas públicas como privadas, permite maior controle sobre os sistemas de ensino, sobre o que as escolas ensinam e como ensinam, e esse controle está intimamente relacionado com os processos de avaliação.

Outro marco para a alfabetização foi a recente aprovação do Programa Tempo de Aprender, o qual está orientado pela Portaria $\mathrm{n}^{\circ}$ 280, de 19 de fevereiro de 2020 (BRASIL, 2020b), que institui o referido Programa e dispõe sobre a alfabetização escolar no âmbito do Governo Federal. O Programa foi desenvolvido a partir das diretrizes da Política Nacional de Alfabetização (PNA) e é destinado para a pré-escola e ao $1^{\circ}$ e $2^{\circ}$ anos do Ensino Fundamental das redes públicas estaduais, distrital e municipais.

O Programa Tempo de Aprender está organizando em quatro eixos: Eixo I - Formação continuada de profissionais da alfabetização, que se efetivará por meio de cursos presenciais e a distância aos professores alfabetizadores, curso de capacitação em gestão educacional para diretores e coordenadores e intercâmbio de professores alfabetizadores; Eixo II - Apoio pedagógico para a alfabetização, que se efetivará por meio da utilização da ferramenta do Sistema On-line de Recursos para Alfabetização (Sora), apoio financeiro a assistente de alfabetização e custeio para escolas, também reformulação do Programa Nacional do Livro Didático (PNLD) para a Educação Infantil e anos iniciais do Ensino Fundamental; Eixo III - aprimoramento das avaliações da alfabetização, que será tratado posteriormente com mais ênfase; e Eixo IV - valorização dos profissionais da alfabetização por meio da instituição de premiação para professores alfabetizadores (BRASIL, 2020c).

\footnotetext{
9 “A Pirâmide de Kelsen é uma abstração que apresenta a ideia de ordenamento jurídico, por meio da hierarquização das normas jurídicas estruturadas. A norma mais importante ocupa o topo da Pirâmide e subordina as demais normas jurídicas de hierarquia inferior" (FERNANDES; COLVERO, 2019, p. 300).
} 
A partir das políticas voltadas à alfabetização observamos, nesta seção, a discordância entre a legislação no que tange ao tempo destinado à alfabetização. Além disso, percebemos a centralidade que a alfabetização ganhou a partir da BNCC, principalmente por meio do Programa Mais Alfabetização, da Política Nacional de Alfabetização e do Programa Tempo de Aprender. Com a restruturação do SAEB, a avaliação da alfabetização foi antecipada para o $2^{\circ}$ ano do Ensino Fundamental, justamente por estar em consonância com a BNCC. Com isto, constatamos a pressão e o controle cada vez mais acirrados com os alfabetizandos, assim como com os professores alfabetizadores.

Desconsidera-se, portanto, o tempo da criança, suas necessidades individuais para compreender a complexidade da leitura e da escrita, e o professor acaba sofrendo com a pressão para a alfabetização cada vez mais precoce. A partir dessas colocações, buscamos observar, na próxima seção, como os documentos posteriores à BNCC mais recentemente aprovados, que orientam a alfabetização, contemplam a avaliação em larga escala por meio dos novos mecanismos de controle e responsabilização.

\section{PERSPECTIVA DE AVALIAÇ̃̃o EM LARGA ESCALA NOS DOCUMENTOS REFERENTES À ALFABETIZAÇ̃̃o APÓS A APROVAC̈̃̃ DA BNCC}

A BNCC vem como demanda do Estado para fortalecer ainda mais o controle sobre a educação via avaliações em larga escala.

Na luta pelo controle do processo pedagógico das escolas, o Estado é cada vez mais disputado por forças sociais liberal-conservadoras que procuram assumir, por meio de avaliações externas, o controle e o fortalecimento dos processos de avaliação internos da escola (formais e informais) e a partir destes subordinar as categorias do processo pedagógico a seus interesses, vale dizer, preservar e aumentar o controle sobre os objetivos, o conteúdo e até sobre os métodos da escola (FREITAS, 2014, p. 1092).

Assim, inibe práticas pedagógicas mais progressistas e induz a uma padronização do trabalho docente, visando a atender às necessidades produtivas do capitalismo, no qual o básico é o suficiente para o trabalhador.

Nesta perspectiva, buscamos identificar, nos documentos, excertos que evidenciam os novos mecanismos de controle via processos avaliativos em larga escala. Procurando entender como as políticas de avaliação se configuraram após a aprovação da BNCC e como passaram a influenciar a etapa de alfabetização, elencamos os documentos mais recentes voltados para essa etapa de ensino, na intenção de identificar como eles contemplam a questão da avaliação em larga escala. Os documentos analisados foram:

1 - Portaria n 142, de 22 de fevereiro de 2018 - Institui o Programa Mais Alfabetização, que visa a fortalecer e apoiar as unidades escolares no processo de alfabetização dos estudantes regularmente matriculados nos $1^{\circ}$ e $2^{\circ}$ anos do Ensino Fundamental (BRASIL 2018b);

2 - Decreto no 9.765, de 11 de abril de 2019, o qual instituiu a Política Nacional de Alfabetização (PNA) (BRASIL, 2019a);

3 - Cartilha da Política Nacional de Alfabetização (BRASIL, 2019b); e

4 - Portaria $n^{\circ}$ 280, de 19 de fevereiro de 2020, que instituiu o Programa Tempo de Aprender, que dispõe sobre a alfabetização escolar no âmbito do Governo Federal (BRASIL, 2020b).

A partir dessa seleção identificamos, nos documentos, excertos que demonstram como as avaliações em larga escala estão contempladas na alfabetização. A seguir, apresentamos o Quadro 1, com essas informações. 


\begin{tabular}{|c|c|c|}
\hline DOCUMENTO & EXCERTOS DO DOCUMENTO & $\begin{array}{l}\text { ITEM AO QUAL } \\
\text { PERTENCE }\end{array}$ \\
\hline \multirow[t]{2}{*}{$\begin{array}{l}\text { Portaria } n^{\circ} 142 \text {, } \\
\text { de } 22 \text { de fevereiro } \\
\text { de } 2018\end{array}$} & $\begin{array}{l}\text { Art. } 3^{\circ} \text { São diretrizes do Programa Mais Alfabetização: [...] } \\
\text { V - estipular metas do Programa entre o Ministério da Educação } \\
\text { - MEC, os entes federados e as unidades escolares participantes no } \\
\text { que se refere à alfabetização das crianças do } 1^{\circ} \text { e } 2^{\circ} \text { ano do Ensino } \\
\text { Fundamental, considerando o disposto na BNCC; } \\
\text { VI - assegurar o monitoramento e a avaliação periódica da execução } \\
\text { e dos resultados do Programa. }\end{array}$ & $\begin{array}{l}\text { Capítulo II } \\
\text { das Diretrizes do } \\
\text { Programa (p. 54) }\end{array}$ \\
\hline & $\begin{array}{l}\text { Art. } 6^{\circ} \text { Compete ao MEC: [...] III - criar e implementar mecanismos } \\
\text { de monitoramento a serem incorporados à rotina das secretarias e } \\
\text { gestão escolar, por meio de avaliações diagnósticas e formativas. }\end{array}$ & $\begin{array}{l}\text { Capítulo IV } \\
\text { Das Competências } \\
(\text { p. 55) }\end{array}$ \\
\hline $\begin{array}{l}\text { Decreto } \mathrm{N}^{\circ} 9.765 \text {, } \\
\text { de } 11 \text { de abril de } \\
2019\end{array}$ & $\begin{array}{l}\text { Art. } 9^{\circ} \text { Constituem mecanismos de avaliação e monitoramento da } \\
\text { Política Nacional de Alfabetização: } \\
\text { I - avaliação de eficiência, eficácia e efetividade de programas e } \\
\text { ações implementados; } \\
\text { II - incentivo à difusão tempestiva de análises devolutivas de } \\
\text { avaliações externas e ao seu uso nos processos de ensino e de } \\
\text { aprendizagem; } \\
\text { III - desenvolvimento de indicadores para avaliar a eficácia escolar na } \\
\text { alfabetização; } \\
\text { IV - desenvolvimento de indicadores de fluência em leitura oral e } \\
\text { proficiência em escrita; e } \\
\text { V - incentivo ao desenvolvimento de pesquisas acadêmicas para avaliar } \\
\text { programas e ações desta Política. }\end{array}$ & $\begin{array}{l}\text { Capítulo VI } \\
\text { Da Avaliação e } \\
\text { Monitoramento } \\
\text { (p. 16) }\end{array}$ \\
\hline $\begin{array}{l}\text { Caderno da } \\
\text { Política Nacional } \\
\text { de Alfabetização } \\
\text { (PNA) }\end{array}$ & $\begin{array}{l}\text { A avaliação e o monitoramento constituem parte essencial de } \\
\text { uma política pública. Quando se tem em vista o objetivo proposto, } \\
\text { a produção de resultados confiáveis, a identificação de problemas no } \\
\text { percurso e a eficácia no uso de recursos públicos, fica evidente a } \\
\text { importância desses mecanismos. }\end{array}$ & $\begin{array}{l}\text { Avaliação e } \\
\text { Monitoramento } \\
\text { (p. 45) }\end{array}$ \\
\hline $\begin{array}{l}\text { Portaria } \mathrm{n}^{\mathbf{0}} \\
\mathbf{2 8 0} \text {, de } \mathbf{1 9} \text { de } \\
\text { fevereiro de } \\
2020 \text { - Institui O } \\
\text { Programa Tempo } \\
\text { de Aprender }\end{array}$ & $\begin{array}{l}\text { Art. } 2^{\circ} \text { O Programa será organizado nos seguintes eixos, com suas } \\
\text { respectivas ações: } \\
\text { [...] } \\
\text { III - eixo Aprimoramento das avaliações da alfabetização: } \\
\text { a) aplicação de diagnóstico formativo de fluência em leitura; } \\
\text { b) aperfeiçoamento das avaliações do Sistema de Avaliação da } \\
\text { Educação Básica - Saeb voltadas à alfabetização; e } \\
\text { c) avaliação de impacto do Programa. } \\
\text { IV - eixo Valorização dos profissionais da alfabetização por meio da } \\
\text { instituição de premiação para professores alfabetizadores. }\end{array}$ & $\begin{array}{l}\text { Capítulo I } \\
\text { das Disposições } \\
\text { Gerais - Art. } 2^{\circ}(p \text {. } \\
\text { 69) }\end{array}$ \\
\hline
\end{tabular}

\section{FONTE: ELABORADO PELAS AUTORAS A PARTIR DE BRASLL (2018B; 2019A; 2019B; 2020B, GRFFOS NOSSOS).}

Por meio desses documentos, podemos observar que a questão avaliativa está contemplada, voltando-se principalmente para a proposta de melhores índices e resultados da alfabetização.

A proposta de avaliação assenta-se no desenvolvimento de indicadores e no estabelecimento de metas educacionais, sendo a avaliação vista como essencial para o controle dos recursos públicos, enfatizando a necessidade de uma boa gestão desses recursos para que haja maior eficiência.

Essa perspectiva que observamos nos documentos está voltada para o modelo gerencialista e de quase mercado, pois passam a ser incorporados mecanismos e ações do setor privado na gestão de instituições públicas, ou seja, toma-se como referência a gestão do mercado para gerenciar a educação. 
Isso porque uma das justificativas dadas pelo ideário neoliberal é de que as escolas não fazem uma boa gestão dos recursos.

Esse discurso e orientação possuem como base a defesa da eficiência, da eficácia e produtividade dos sistemas educacionais, a fim de que possam atingir índices e metas. Assim, os mecanismos de controle e responsabilização que incidem sobre a escola e professores alfabetizadores é muito grande, visto que o alcance de bons resultados passa a ser de sua responsabilidade.

Nesse contexto, podemos identificar como o ideário neoliberal se faz presente no âmbito educacional. O modelo neoliberal, que defende o afastamento do Estado das questões sociais, a privatização de serviços e empresas públicas, mecanismos de desregulamentação, entre outros princípios (TORRES, 1996), também é um modelo que interfere na educação. Entre suas ações estão a regulação e o controle dos sistemas educacionais, e podemos identificar que essas ações são efetivadas via implantação de sistemas de avaliação (AFONSO, 2009).

O Estado assume, dessa forma, a postura de Estado-avaliador que, ao mesmo tempo que se afasta das questões e responsabilidades sociais, é um Estado que avalia e controla, para que as redes de ensino e propriamente as escolas sejam eficientes e produtivas a ponto de alcançar as metas estipuladas por ele. Podemos identificar no contexto brasileiro, a partir dos estudos de Afonso (2009), que a criação do Índice de Desenvolvimento da Educação Básica (IDEB) estabelece um ranking educacional, em que as escolas são responsabilizadas pelo sucesso ou fracasso escolar.

Com isso, desconsidera-se toda a diversidade cultural, social, histórica e econômica das escolas, que acabam sendo padronizadas a um único Sistema de Avaliação da Educação Básica. Além disso, são deixados de lado os aspectos externos da escola, que também influenciam nos resultados: um deles é a própria desigualdade social que historicamente se faz presente no país.

As leituras realizadas apontam para uma questão presente no âmbito da alfabetização: nem todas crianças têm acesso a um amplo meio letrado, nem todas têm famílias com tempo e condições de escolaridade que possam ajudar nas tarefas escolares; e o mais grave, nem todas têm os meios de subsistência necessários para viver, como roupa e comida. Então, por que pressionar tanto as crianças para que saiam do $1^{\circ}$ ano lendo e escrevendo? Será que o que mais importa são os índices? Precisamos considerar o tempo de aprendizagem de cada criança, e buscar proporcionar os mais diversos e necessários meios para a alfabetização e o letramento, principalmente daquelas crianças que mais necessitam da escola.

\section{CONSIDERAÇÕES FINAIS}

Com as novas orientações da BNCC, do PMALFA, da PNA e do Programa Tempo de Aprender, a ênfase que recai sobre o professor alfabetizador é muito grande. Não queremos afirmar, com isso, que o professor não é parte fundamental do processo de alfabetização. Porém, não é o único responsável. No entanto, “[...] a responsabilização desse profissional por problemas cujas origens extrapolam a educação escolar e encontram-se nas relações sociais de produção capitalistas, nas conflituosas relações de classe, na relação capital-trabalho" (PEREIRA; EVANGELISTA, 2019, p. 80). Nesse sentido, entendemos que um processo de aprendizagem, para se efetivar, necessita de elementos fundamentais, tais como espaço apropriado, profissionais da educação com salários adequados e dignos, e funções condizentes com a sua formação, escola que tenha apoio pedagógico, materiais disponíveis e condições mínimas estruturais.

Portanto, pensamos as políticas educacionais brasileiras em um contexto muito mais amplo, no âmbito de uma sociedade capitalista, que tem determinado projeto de educação. Entendido isto, refletimos sobre como ficam os processos de avaliação nacional para a etapa da alfabetização, e o que acontece no cenário brasileiro a partir da aprovação da BNCC, que tem implicações diretas na formação de professores, na elaboração de materiais didáticos, nas avaliações, e em muitas outras políticas.

A partir da contextualização dos marcos políticos e documentais, observamos como a alfabetização tem ganhado centralidade na agenda política brasileira, principalmente com a criação da Secretaria de Alfabetização (SEALF), em 2019, a qual vem atuando fortemente em ações voltadas à alfabetização. 
Por meio da análise dos documentos, observamos como a questão da avaliação se faz presente. Um dos marcos importantes no âmbito da avaliação foi a reestruturação do SAEB como uma das demandas da BNCC. Com essa nova configuração, a Avaliação Nacional da Alfabetização (ANA), criada em 2013, deixa de existir, mas a alfabetização continua sendo avaliada por meio de uma avaliação própria do SAEB para essa etapa, mas aplicada para o $2^{\circ}$ ano, diferentemente da ANA, que era aplicada no $3^{\circ}$ ano do Ensino Fundamental, atendendo à BNCC, que prevê a alfabetização até o $2^{\circ}$ ano.

As políticas voltadas para alfabetização que surgiram após a BNCC também vão ao encontro dessa antecipação do processo de alfabetização, tal como no Programa Mais Alfabetização, na Política Nacional da Alfabetização (PNA), que prioriza a alfabetização no $1^{\circ}$ ano do Ensino Fundamental, assim como no Programa Tempo de Aprender, que parte das diretrizes da PNA.

Todos os documentos referentes a essas políticas apresentam uma relação com as políticas de avaliação, que também se fazem presentes no contexto alfabetizador. Com a recente criação do Programa Tempo de Aprender, essa relação fica muito mais evidente, visto que está prevista a realização de uma avaliação de fluência de leitura e novas mudanças no SAEB, no que se refere à alfabetização. Além disso, um dos eixos do Programa incentiva a valorização docente mediante premiação aos professores alfabetizadores, diretores e coordenadores pedagógicos que tiverem bom desempenho, aferido por meio de uma avaliação externa (BRASIL, 2020c). Com essa ação, os mecanismos de accountability e responsabilização docente pelos resultados educacionais se tornam ainda mais intensos; e a etapa de alfabetização mostra claros traços de mecanismos de controle.

\section{REFERÊNCIAS}

AFONSO, A. J. Avaliação educacional: regulação e emancipação. 4º ed. São Paulo: Cortez, 2009.

AMARANTE, L.; MOREIRA, J. A. S.. Políticas curriculares para alfabetização: questões e dilemas a partir da BNCC. Jornal de Políticas Educacionais - Núcleo de Políticas Educacionais da Universidade Federal do Paraná - NuPE/UFPR, Curitiba, v. 13, n. 42, p. 01- 23, nov. 2019. Disponível em: https://revistas.ufpr.br/jpe/article/view/66587. Acesso em: 04 jan. 2020.

BORTOLANZA, A. M. E.; GOULART, I. C. V.; CABRAL, G. R. Diferentes perspectivas de alfabetização a partir da Base Nacional Comum Curricular: concepções e desafios. Ensino Em ReVista, Uberlândia - MG, v. 25, n. Especial, p. 958 - 983, dez. 2018. Disponível em: http://www.seer. ufu.br/index.php/emrevista/article/view/46452. Acesso em: 03 jan. 2020.

BRASIL. Decreto n ${ }^{\circ}$ 9.765, de 11 de abril de 2019. Institui a Política Nacional de Alfabetização.

Diário Oficial [da] República Federativa do Brasil, Brasília, edição extra de 11/04/2019a - no 70 -A, p. 15, col. 2. Seção 1. Disponível em: https://legis.senado.leg.br/norma/30902116. Acesso em: 25 jan. 2019.

BRASIL. MEC anuncia Política Nacional de Alfabetização para reverter quadro de estagnação na aprendizagem. 2017b. Disponível em: http://portal.inep.gov.br/artigo/-/asset_publisher/ B4AQV9zFY7Bv/content/mec-anuncia-politica-nacional-de-alfabetizacao-para-reverter-quadro-deestagnacao-na-aprendizagem/21206. Acesso em: 15 set. 2019.

BRASIL. Ministério da Educação. Planejando a próxima década: conhecendo as 20 metas do Plano Nacional de Educação. Brasília: MEC, 2014. Disponível em: http://pne.mec.gov.br/images/pdf/pne_ conhecendo_20_metas.pdf. Acesso em: 18 mar. 2018.

BRASIL. Ministério da Educação. Política Nacional de Alfabetização - Conta pra Mim. Disponível em: http://alfabetizacao.mec.gov.br/\#para-pais. Acesso em: 21 jan. 2020a. 
BRASIL. Ministério da Educação. Portaria nº 142, de 22 de fevereiro de 2018. Institui o Programa Mais Alfabetização, que visa fortalecer e apoiar as unidades escolares no processo de alfabetização dos estudantes regularmente matriculados no $1^{\circ}$ ano e no $2^{\circ}$ ano do ensino fundamental. Diário Oficial [da] República Federativa do Brasil, Brasília, ed. 37, p. 54-55, 23 fev. 2018b. Seção 1. Disponível em: http://www.in.gov.br/web/dou/-/portaria-n-142-de-22-de-fevereiro-de-2018-4220037. Acesso em: 13 dez. 2019.

BRASIL. Ministério da Educação. Portaria no 280, de 19 de fevereiro de 2020 - Institui o Programa Tempo de Aprender, que dispõe sobre a alfabetização escolar no âmbito do Governo Federal.

Diário Oficial [da] República Federativa do Brasil, Brasília, ed. 37, p. 69, 21 fev. 2020b. Seção 1. Disponível em: http://www.in.gov.br/en/web/dou/-/portaria-n-280-de-19-de-fevereirode-2020-244584539. Acesso em: 25 mar. 2020.

BRASIL. Ministério da Educação. Portaria n 826, de 7 de julho de 2017. Dispõe sobre o Pacto Nacional pela Alfabetização na Idade Certa - PNAIC, suas ações, diretrizes gerais e a ação de formação no âmbito do Programa Novo Mais Educação - PNME. Diário Oficial [da] República Federativa do Brasil, Brasília, ed. 130, p. 20, 10 de jul. 2017a. Seção 1. Disponível em: http://www. in.gov.br/web/dou/-/portaria-n-826-de-7-de-julho-de-2017-19166666. Acesso em: 20 dez. 2019.

BRASIL. Ministério da Educação. Programa de alfabetização será prioridade em 2020. Entrevista: Carlos Nadalim. 2019c. Disponível em: http://portal.mec.gov.br/component/content/index. php?option=com_content\&view=article\&id=83991:programa-de-alfabetizacao-sera-prioridade-em2020\&catid=12\&Itemid=86. Acesso em: 20 jan. 2020.

BRASIL. Ministério da Educação. Provinha Brasil. 2015. Disponível em: http://portal.inep.gov.br/ provinha-brasil. Acesso em: 15 set. 2019.

BRASIL. Ministério da Educação. Secretaria de Alfabetização. PNA Política Nacional de Alfabetização/Secretaria de Alfabetização. - Brasília: MEC, SEALF, 2019b. 54 p. Disponível em: http://portal.mec.gov.br/images/banners/caderno_pna_final.pdf. Acesso em: 26 jan. 2020.

BRASIL. Ministério da Educação. Secretaria de Educação Básica. Base Nacional Curricular Comum (BNCC), Brasília, DF, 2018a. Disponível em: http://basenacionalcomum.mec.gov.br/ wpcontent/uploads/2018/06/BNCC_EI_EF_110518_versaofinal_site.pdf. Acesso em: 20 mar. 2019.

BRASIL. Ministério da Educação. Tempo de Aprender. Disponível em: http://alfabetizacao.mec.gov. br/tempo-de-aprender. Acesso em: 30 mar. 2020c.

D’AVILA, J. B. As influências dos agentes públicos e privados no processo de elaboração da Base Nacional Comum Curricular. 2018. 130 p. Dissertação (Mestrado em Educação) - Universidade Estadual do Centro Oeste, Guarapuava, 2018. Disponível em: http://tede.unicentro.br:8080/jspui/ handle/jspui/1157. Acesso em: 14 nov. 2018.

FERNANDES, S. B.; COLVERO, R. B. Políticas públicas educacionais contraditórias: a alfabetização em foco. Revista on line de Política e Gestão Educacional, Araraquara, v. 23, n. 2, p. 286-305, maio/ ago.2019. Disponível em: https://periodicos.fclar.unesp.br/rpge/article/view/11963. Acesso em: 02 jan. 2020.

FREITAS, L. C. Os reformadores empresariais da educação e a disputa pelo controle do processo pedagógico na escola. Educ. Soc., Campinas, v. 35, nº 129, p. 1085-1114, out.-dez., 2014. Disponível em: http://www.scielo.br/pdf/es/v35n129/0101-7330-es-35-129-01085.pdf. Acesso em: 05 set. 2018.

FRIGOTTO, G.; CIAVATTA, M. Educação Básica o Brasil na década de 1990: subordinação ativa e consentida à lógica do mercado. Educ. Soc., Campinas, v. 24, n. 82, p. 93-130, abril 2003. Disponível em: http://www.scielo.br/pdf/es/v24n82/a05v24n82.pdf. Acesso em: 07 set. 2018. 
GRAMSCI, A. Maquiavel, a Política e o Estado Moderno. Rio de Janeiro: Civilização Brasileira, 1968.

LIMA, M. F. Roque Spencer Maciel de Barros: pensamento e intervenção na Reforma Universitária de 1968. Dissertação (Mestrado em Educação) - Programa de Pós-Graduação em Educação da Universidade Estadual de Maringá, 2005. Disponível em: http://www.dominiopublico.gov.br/pesquisa/ DetalheObraForm.do?select_action=\&co_obra=119641. Acesso em: 13 ago. 2019.

PEREIRA, J. N.; EVANGELISTA, O. Quando o capital educa o educador: BNCC, Nova Escola e Lemann. Movimento-Revista de Educação, Niterói, ano 6, n.10, p. 65-90, jan./jun. 2019. Disponível em: http://periodicos.uff.br/revistamovimento/article/view/32664/18804. Acesso em: 04 set. 2019.

SILVA, M. A. Intervenção e Consentimento: a política educacional do Banco Mundial. Campinas, São Paulo: Autores associados, 2002.

TORRES, C. A. Estado, Privatização e Política Educacional Elementos Para Uma Crítica do Neoliberalismo. In: GENTILLI, Pablo. Pedagogia da exclusão: crítica ao neoliberalismo em educação. $2^{\circ}$ ed. Petrópolis, RJ: Vozes, 1996. p.109- 136. 